\title{
Pengaruh Kinesio Taping dan Abduction Brace Terhadap Panjang Otot Adduktor Hip pada Anak Palsi Serebral Tipe Spastik Diplegi
}

Selvi Natsir, Mita Noviana, Dwi Rustyanto

Program Studi Fisioterapi Fakultas Kedokteran Universitas Hasanuddin, Makassar

Latar belakang. Anak palsi serebral tipe spastik diplegi mengalami peningkatan tonus pada beberapa otot, salah satunya adalah otot adduktor hip, akibatnya tungkai mengalami kekakuan yang akan berdampak pada perkembangan anak.

Tujuan. Menilai pengaruh kinesio taping dan abduction brace dalam mengubah tonus otot dan meningkatkan panjang otot adduktor. Metode. Desain penelitian yang digunakan adalah pra-eksperimental dengan responden terdiri dari 15 anak palsi serebral tipe spastik diplegi yang berusia 2-13 tahun. Data yang dikumpulkan meliputi nilai tonus otot dan panjang otot adduktor yang dievaluasi menggunakan skala Ashworth dan manual goniometer sebelum dan sesudah 6 kali intervensi.

Hasil. Terdapat perbedaan sebelum dan setelah intervensi dinilai dengan skala Asworth mengalami penurunan ( $\mathrm{p}=0,002)$, sedangkan panjang otot adduktor mengalami peningkatan $(\mathrm{p}=0,000)$. Hasil korelasi negatif yang signifikan juga diperoleh antara tingkat spastisitas dengan panjang otot adduktor $(r=0,866 ; p=0,000)$.

Kesimpulan. Kombinasi kinesio taping dan abduction brace dapat meningkatkan panjang otot adduktor hip melalui penurunan tonus otot pada anak palsi serebral tipe spastik diplegi. Sari Pediatri 2017;18(5):379-84

Kata kunci : palsi serebral, kinesio taping, abduction brace

\section{Effect of Kinesio Taping and Abduction Brace on Hip Adductor Muscle Length in Children With Spastic Diplegi Cerebral Palsy}

Selvi Natsir, Mita Noviana, Dwi Rustyanto

Background. Children with spastic diplegi cerebral palsy experience increased tone on their muscles, one of which is hip adductor muscle, the increased muscle tone will cause limb stiffness that will have an impact on children's development.

Objective. This study aimed to identify the effects of Kinesio taping and abduction brace in changing muscle tone, also in improving the adductor muscle length.

Methods. The study used a pre-experimental design with 15 children with spastic diplegi cerebral palsy 2-13 years of age. The data that collected are mucle tone score and the length of hip adductor muscle which evaluated by ashworth scale and manual goniometer. It measured before intervention and after 6 times intervention.

Results. There were differences before and after intervention, where decreasing asworth score $(\mathrm{p}=0.002)$ and increasing the adductor muscle length $(\mathrm{p}=0.000)$. There is an significant negative correlation between spastisity level and adductor muscle length ( $\mathrm{r}=0,866$; $\mathrm{p}=0,000)$.

Conclusion. This study showed that the combination of kinesio taping and abduction brace can increase hip adductor muscle length by decreasing muscle tone in children with spastic diplegi cerebral palsy. Sari Pediatri 2017;18(5):379-84

Keywords : cerebral palsy, kinesio taping, abduction brace

Alamat korespondensi: Selvi Natsir. Perintis Kemerdekaan KM 12 No.46, Makassar, 90245 Indonesia. Hp: 0852-2429-1315. Email: selvinatsir@gmail. com,mita.noviana@ymail.com,ypacmakassar@yahoo.co.id 
$\mathrm{P}$ alsi serebral atau cerebral palsy (CP) merujuk pada sejumlah kelainan neurologis yang tampak saat bayi akibat lesi otak yang sedang berkembang. Akibat lesi yang terjadi pada berbagai bagian otak, manifestasi klinis yang dihasilkan memiliki ciri khas tersendiri. Berdasarkan manifestasi tersebut CP diklasifikasikan dalam beberapa tipe, seperti tipe spastik, diskinetik, ataxic, dan berdasarkan topografi tubuh yang mengalami gangguan $\mathrm{CP}$ diklasifikasikan menjadi hemiplegi, diplegi, dan quadriplegi. ${ }^{1}$

Studi di negara bagian Autralia yang dilakukan Autralian cerebral palsy register yang menunjukkan 2,1 per 1.000 kelahiran anak menderita CP. Terdapat 3.135 individu dengan CP yang lahir pada tahun 1993-2006. Data yang didapatkan dari studi kohort menunjukkan CP tipe spastik dengan persentase terbanyak (86,5\%). Di antara CP tipe spastik tersebut, berdasarkan topografi tubuh yang mengalami disorder, spastik bilateral (diplegi, tripelgi, quadriplegi) mendominasi $61,2 \%$ dan spastik unilateral (hemiplegi termasuk monoplegia) sebesar 38,8\%. ${ }^{2}$

Pada berbagai studi yang dilakukan di berbagai negara, rata-rata $\mathrm{CP}$ tipe spastik bilateral termasuk spastik diplegi yang mendominasi. Kelainan CP spastik diplegi adalah CP yang memiliki ciri khas, yaitu penurunan kontrol kedua ektremitas bawah yang lebih besar dibanding ekstremitas atas. ${ }^{3}$ Penurunan kontrol ektremitas akibat gangguan upper motor neuron mengakibatkan penderita spastik diplegi mengalami hipertonus pada hip fleksor, hamstring, serta adduktor. Spastisitas yang terjadi pada adduktor serta muscle imbalance dapat berkembang menjadi deformitas pada tungkai. ${ }^{4}$ Deformitas yang banyak terjadi adalah kontraktur otot adduktor hip (menurunnya esktenbilitas otot) yang juga menyebabkan tungkai anak membentuk pola menggunting atau scissor. ${ }^{5}$

Tonus yang tinggi mengakibatkan pergerakan tungkai anak terhalang dan akan menyulitkan perkembangan milestone seperti duduk, merangkak, hingga berjalan. Satu tahapan perkembangan milestone anak mengalami delayed akan menyulitkan untuk dapat ke tahap perkembangan selanjutnya sebab perkembangan skill anak dibentuk oleh skill yang telah didapatkan sebelumnya. ${ }^{6}$

Intervensi untuk mencegah atau mengurangi kontraktur dan membuat panjang otot maksimal dilakukan dengan memberikan stimulus mekanik untuk menginduksi fungsi jaringan otot. Dengan memberikan latihan hingga pemakaian alat menjadi modalitas terpenting dalam rehabilitasi anak CP. Orthosis seperti abduction brace yang kaku dapat menjadi pilihan dalam mencegah deformitas seperti kontraktur pada otot adduktor. ${ }^{4}$ Pemakaian kinesio taping dianggap dapat memfasilitasi dan menginhibisi fungsi otot dari respon proprioseptif melalui mekanoreseptor yang berada pada kulit, tendon, otot, dan sendi. ${ }^{78}$ Pemakaian kinesio taping pada anak CP relatif jarang digunakan dalam program rehabilitasi pediatrik.

Kombinasi abduction brace dan kinesio taping menjadi fokus dalam penelitian untuk mengetahui pengaruh yang ditimbulkan terhadap panjang otot adduktor hip dan tonus otot ektremitas inferior.

\section{Metode}

Rancangan penelitian yang digunakan adalah preeksperimental dengan metode one-group pretest posttest design. Penelitian ini dilakukan pada anak yang berobat di klinik Fisioterapi YPAC Makassar. Populasi dalam penelitian ini adalah CP spastik diplegi di klinik tersebut. Subjek diambil sesuai dengan kriteria inklusi, yaitu dapat menggunakan abduction brace (leg splint kaku) dan tidak mengalami dislokasi hip dan bersedia menjadi subjek penelitian. Sampel diekslusi jika tidak rutin datang ke klinik Fisioterapi YPAC Makassar, memiliki kulit yang sensitif terhadap tape atau bahan adesif, dan mengalami penyakit kulit pada area tungkai Berdasarkan kriteria tersebut didapatkan 15 anak yang terdiri dari 7 laki-laki dan 8 perempuan berusia 2 - 13 tahun.

Pengumpulan data dilakukan dengan mengukur tingkat spastisitas ekstremitas inferior melalui fleksor knee menggunakan Ashworth scale dan mengukur panjang otot adduktor hip menggunakan manual goniometer. Hal tersebut dilakukan sebelum dan setelah pemberian intervensi berupa kinesio taping dan abduction brace.

Intervensi diberikan sebanyak enam kali, tiga kali seminggu dengan interval 1 hari istirahat. Abduction brace diberikan terlebih dahulu selama 30 menit, didahulu dengan pemakaian AFO (ankle foot orthose) dalam posisi ankle $90^{\circ}$, leg brace, kemudian abduction brace. Jarak dari abduction brace disesuaikan dengan kemampuan subjek (panjang abduction brace dapat ditingkatkan saat sampel menunjukkan luas gerak sendi yang meningkat dan abduction brace yang digunakan 
memiliki pengaturan panjang sekrup, dengan jarak antar tiap sekrup adalah $5 \mathrm{~cm}$ ).

Kinesio taping (KT) diberikan selama 24 jam dengan metode fasilitasi abduksi dan fasilitasi knee lateral rotasi, kedua metode ini biasa disebut fasilitasi knee lateral rotasi. Orang tua atau pengasuh diedukasi untuk melepas KT. Data hasil pretest dan post test dianalisis menggunakan perangkat SPSS 17.0 untuk windows dengan menggunakan pengujian komparatif berupa uji $\mathrm{T}$ berpasangan atau Wilcoxon.

\section{Hasil}

Tingkat spastisitas sebelum intervensi didominasi responden yang mengalami spastisitas dengan nilai Asworth 3 dan 4 (73,33\%) dan setelah mendapatkan intervensi didominasi dengan nilai 1 dan $2(73,33 \%)$. Sebelum intervensi panjang otot adduktor Hip yang jaraknya lebih dari $31^{\circ}$ hanya didapatkan pada $6,66 \%$ (tungkai dextra) dan 13,33\% (tungkai sinistra), setelah intervensi untuk kedua tungkai sebanyak $40 \%$ responden berada pada rentang lebih dari $31^{\circ}$.

Semua 15 responden, menunjukkan peningkatan panjang otot adduktor hip pada kedua tungkai. Sebelum pemberian abduction brace dan kinesio taping rerata luas gerak abduksi sendi hip dextra dan sinistra

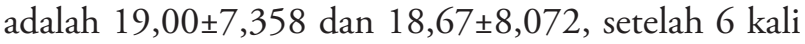
intervensi luas gerak abduksi sendi hip dextra dan sinistra menjadi $30,13 \pm 10,350$ dan $30,07 \pm 10,620$ $(\mathrm{p}=0,000)$. Distribusi nilai tonus otot ekstremitas inferior menunjukkan penurunan dari nilai median 2,87 sebelum mendapatkan intervensi menjadi 2,13 setelah diberikan abduction brace dan kinesio taping $(\mathrm{p}=0,002)$.

Uji korelasi antar tingkat spastisitas dengan panjang otot adduktor kedua tungkai dari 15 responden menunjukkan korelasi antar variabel dengan

Tabel 1. Distribusi frekuensi sampel berdasarkan panjang otot adduktor

\begin{tabular}{lcccc}
\hline Luas gerak abduksi & \multicolumn{3}{c}{ Frekuensi } \\
\cline { 2 - 5 } & \multicolumn{3}{c}{ Pretest } & \multicolumn{3}{c}{ Postest } \\
\cline { 2 - 5 } & $7(46,67)$ & $7(46,67)$ & $2(13,33)$ & $2(13,33)$ \\
\hline $0^{0}-15^{0}$ & $7(46,67)$ & $6(40)$ & $7(46,67)$ & $7(46,67)$ \\
$16^{0}-30^{\circ}$ & $1(6,66)$ & $2(13,33)$ & $6(40)$ & $6(40)$ \\
$>31^{0}$ & $15(100)$ & $15(100)$ & $15(100)$ & $15(100)$ \\
$\mathrm{n}$ & & & & Sinistra $)$ \\
\hline
\end{tabular}

n total sampel dalam penelitian

Tabel 2. Distribusi frekuensi sampel berdasarkan tingkat spastisitas

\begin{tabular}{lcc}
\hline Nilai Ashworth & \multicolumn{2}{c}{ Frekuensi } \\
\cline { 2 - 3 } & Pretest $(\%)$ & Posttest $(\%)$ \\
\hline 0 & $0(0)$ & $0(0)$ \\
1,2 & $4(26,67)$ & $11(73,33)$ \\
3,4 & $11(73,33)$ & $4(26,67)$ \\
$\mathrm{n}$ & $15(100$ & $15(100)$ \\
\hline $\mathrm{n}$ adalah total sampel dalam penelitian &
\end{tabular}

Tabel 3. Analisis tingkat spastisitas anak CP spastik diplegi

\begin{tabular}{lccccc}
\hline \multirow{2}{*}{ Tingkat spastisitas } & \multicolumn{5}{c}{ Serebral palsi spastik diplegi $(\mathrm{n}=15)$} \\
\cline { 2 - 5 } & Min & Med & Max & Sig. & p \\
\hline Pretest & 2 & 3 & 4 & 0,003 & 0.002 \\
Posttest & 1 & 2 & 4 & 0,016 & \\
\hline
\end{tabular}

Min=nilai minimum, Med=Nilai median, Max=nilai maksimum. Sig. = probabilitas

uji normalitas Shapiro-wilk, p=probabilitas hasil uji wilcoxon 
Selvi Natsir dkk: Pengaruh kinesio taping dan abduction brace terhadap panjang otot adduktor hip pada palsi serebral tipe spastik diplegi

Tabel 4. Analisis panjang otot adduktor anak CP spastik diplegi

\begin{tabular}{lcccc}
\hline \multirow{2}{*}{ Panjang otot adduktor } & \multicolumn{3}{c}{ Palsi serebral spastik diplegi $(\mathrm{n}=15)$} \\
\cline { 3 - 5 } & & Rerata \pm SB & Sig. & $\mathrm{p}$ \\
\hline \multirow{2}{*}{ Dextra } & Pretest & $19,00 \pm 7,358$ & 0,299 & 0,000 \\
\multirow{2}{*}{ Sinistra } & Posttest & $30,13 \pm 10,350$ & 0,670 & \\
& Pretest & $18,67 \pm 8,077$ & 0,302 & 0,000 \\
& Posttest & $30,07 \pm 10,620$ & 0,131 & \\
\hline
\end{tabular}

Sig. = probabilitas uji normalitas Shapiro wilk; $\mathrm{p}=$ probabilitas hasil uji T berpasangan

Tabel 5. Korelasi tingkat spastisitas dengan panjang otot adduktor

\begin{tabular}{lccc}
\hline & Sig & $\mathrm{p}$ & $\mathrm{r}$ \\
\hline Post test tingkat spastisitas & 0,016 & \multirow{2}{*}{0,000} & $-0,866$ \\
Post test panjang otot adduktor dextra & 0,131 & & \\
Post test tingkat spastisitas & 0,016 & 0,000 & $-0,855$ \\
Post test panjang otot adduktor sinistra & 0,670 & & \\
\hline
\end{tabular}

Sig.=probabilitas uji normalitas Shapiro wilk; p=probabilitas hasil

uji spearman; r=nilai korelasi Spearman Rho

nilai $\mathrm{p}=0,000$. Nilai korelasi Spearman antar tingkat spastisitas dengan panjang otot dextra dan sinistra adalah $\mathrm{r}=0,866$ dan $\mathrm{r}=0,855$. Hasil kedua nilai korelasi tersebut menunjukkan korelasi negatif serta nilai $r$ mendekati -1 yang menunjukkan korelasi sangat kuat.

\section{Pembahasan}

Anak CP mengalami gangguan pada sistem saraf pusat yang menyebabkan pengontrolan tonus otot tidak berjalan baik yang menyebabkan hipertonus. Tonus otot yang berlebih menyebabkan otot secara spontan aktif, menghambat peregangan otot serta terus menerus dalam keadaan kontraksi mengakibatkan sarkomersarkomer pada otot dapat menghilang sehingga menghambat kemampuan otot untuk memanjang sehingga dapat menimbulkan kontraktur yang berimplikasi terhadap penurunan luas gerak sendi. ${ }^{9,10}$

Hasil dalam penelitian ini menunjukkan pengaruh kombinasi pemakaian kinesio taping dan abduction brace terhadap panjang otot adduktor hip melalui perubahan (penurunan) tingkat spastisitas. Hasil tersebut sejalan dengan penelitian yang dilakukan Hagglund dan Wagner ${ }^{10}$ terkait korelasi tingkat spastisitas dengan derajat dorsofleksi ekstremitas inferior pada responden anak cerebral palsy yang menunjukkan anak yang memiliki nilai skala Ashworth yang tinggi mengalami penurunan derajat dorsofleksi dibandingkan dengan anak dengan nilai Ashworth rendah.

Anak CP diplegi mengalami kecenderungan hip adduksi, fleksi dan internal rotasi akibat spastisitas pada adduktor muscle, fleksor hip, dan calf muscle. ${ }^{4}$ Pemakaian kinesio taping dengan metode fasilitasi hip lateral rotasi dilakukan dengan anchor tape diletakkan pada area gluteus (untuk memfasilitasi otot gluteus maximus dan otot gluteus medius yang merupakan otot penggerak abduksi hip) hingga ke medial tungkai atas dan anchor tape yang lain diletakkan pada medial anterior tungkai bawah, ke arah diagonal posterior knee hingga ke medial tungkai atas. ${ }^{11}$

Penggunaan kinesio taping pada area otot gluteus didukung oleh penelitian sebelumnya yang melihat efek kinesio taping terhadap kemampuan ekstensi hip yang menunjukkan hasil ekstensi hip yang lebih besar dibandingkan dengan hasil ekstensi hip yang tidak menggunakan kinesio taping. ${ }^{12}$ Penggunaan kinesio taping pada penelitian terhadap anak CP juga menunjukkan efek positif terhadap postur duduk (kepala, leher, posisi kaki, dan lengan serta fungsi tangan). Kinesio taping diduga memberikan efek positif terhadap mekanoreseptor. Stimulus terhadap mekanoreseptor pada kulit terjadi saat kinesio taping memberikan tarikan dan tekanan terhadap kulit sehingga dimungkinkan terjadinya perubahan 
fisiologis. ${ }^{7}$ Penelitian yang dilakukan Ibrahim untuk melihat efektifitas neuromuskular taping terhadap kemampuan berdiri dan berjalan anak palsi serebral spastik diplegi juga menunjukkan peningkatan yang bermakna. Perubahan tersebut dapat terjadi karena pemakaian taping akan semakin meningkatkan output dari reseptor pada kulit, menstimulasi pusat supraspinal, sehingga meningkatkan posisi sendi dan kinestetik serta keseimbangan. ${ }^{8}$

Penelitian yang dilakukan Rustyanto ${ }^{13}$ pada anak yang mengalami kontraktur otot adduktor hip dengan menggunakan abduction brace juga menunjukkan pengurangan kontraktur otot tersebut. Penggunaan abduction brace akan memberikan pasif stretching pada otot-otot adduktor sehingga akan meregangkan otot. Saat otot teregang, muscle spindle merekam perubahan panjang otot tersebut dan mengirimkan signal tersebut ke medulla spinalis sehingga dengan penggunaan terus menerus muscle spindle mengalami habituasi terhadap panjang yang baru. ${ }^{9}$

Secara fisiologis, ketika otot diregangkan akan timbul refleks kontraksi akibat terstimulusinya muscle spindle, tepatnya reseptor sensori serabut saraf proprioreseptor tipe IA. Akibat eksitasi di reseptor tersebut mengakibatkan medulla spinalis bagian anterior merespon sehingga saraf motorik mengeksitasi otot untuk berkontraksi. Medulla spinalis bagian anterior merupakan bagian yang berperan dalam mengirimkan signal untuk pengaturan tonus otot. Anak CP memiliki kontrol tonus yang terganggu akibat gangguan sistem saraf pusat, sehingga ketika medulla spinalis anterior menerima impuls, respon yang akan diberikan berlebih dan menimbulkan kontraksi yang kuat.

Pada anak CP kinesio taping dan abdution brace diduga membuat jaringan saraf menghantarkan stimulus sensori terkait posisi tungkai dan panjang otot yang seharusnya kepada sistem saraf pusat. ${ }^{7}$ Akibat informasi sensori yang secara rutin diberikan, reseptor pada otot dan kulit dapat mengalami perubahan nilai ambang rangsang (NAR) atau habituasi akibat sensasi yang baru. Sebuah informasi atau stimulus ketika melewati serentetan sinaps pada jaringan saraf, di masa datang akan lebih mudah menjalarkan signal yang sama akibat reseptor yang telah terbiasa menerima informasi yang sama. Proses ini disebut fasilitasi. ${ }^{9}$

Fasilitasi atau perubahan dari efisiensi sinaps diantara dua jaringan saraf hingga aktivasi sinaps yang belum aktif mendasari neuroplastisitas pada jaringan saraf. Neuroplastisitas adalah istilah yang digunakan untuk menjelaskan perubahan dalam fungsi jaringan saraf, perubahan yang terjadi mulai dari level molekular, morfologi, sinapsis, kortikal, hingga fungsional. ${ }^{14}$

Perubahan tonus otot serta panjang otot adduktor hip didapatkan dari kombinasi kinesio taping dan abduction brace yang bekerja untuk memberikan sensasi sensorik yang benar sehingga mengubah NAR pada reseptor, membuat jaringan saraf terfasilitasi sehingga dapat terjadi neuroplastisitas. Kejadian neuroplastisitas pada setiap anak berbeda-beda sebab dipengaruhi oleh faktor kognitif, kemampuan sel sensorik, dan derajat kerusakan pada sistem saraf.

\section{Kesimpulan}

Kombinasi penggunaan kinesio taping dan abduction brace dapat menurunkan tonus otot ektremitas inferior serta meningkatkan panjang otot adduktor hip pada anak palsi serebral tipe spastik diplegi. Penurunan spastisitas pada anak CP akan meningkatkan ekstensibilitas otot sehingga terjadi peningkatan luar gerak sendi. Hasil dalam penelitian ini diharapkan dapat menjadi salah satu rujukan dalam manajemen fisioterapi pediatri. Diharapkan hasil penelitian dapat dikembangkan, terutama dengan melihat dampak tunggal dari kinesio taping terhadap anak palsi serebral.

\section{Daftar pustaka}

1. Berhman RE, Kliegman R. Arvin AM. Nelson ilmu kesehatan anak edisi 15 volume 3. Jakarta: ECG; 2012.

2. Australian Cerebral Palsy Register (ACRP). Australian cerebral palsy report 2013. Carbon Neutral Printing. ACRP; 2013

3. Tugui RD, Antonescu D. Cerebral Palsy Gait, Clinical Importance. J Clin Med 2013;8:388-93.

4. Alexande MA, Matthews DJ. Pediatric rehabilitation principles and practice Edisi ke-4. United State of Amerika: Demos Medical Publications;2010.

5. Poutney T. Physiotherapy for children. China: Elseiver Ltd; 2007.

6. Scharf RJ, Scharaf GJ, Stroustrup A. Developmental milestones. Am Acad Pediatrics 2016;37:25-38.

7. Simsek TT, Turkucuogle B, Cokal N, Ustunbas G, Simsek IE. The effect of kinesio taping on sitting posture, fungctional independence and gross motor function in children with cerebral palsy. Informa Healthcare 2011;33:2053-63.

8. Ibrahim MM. Role of neuromuscular taping on standing and 
Selvi Natsir dkk: Pengaruh kinesio taping dan abduction brace terhadap panjang otot adduktor hip pada palsi serebral tipe spastik diplegi

walking abilities in children with diplegia cerebral palsy. Int J Develop Res 2015;5:5492-5.

9. Guyton AC, Hall JE. Buku ajar fisiologi kedokteran. Jakarta: EGC; 2012.

10. Hagglund G, Wegner P. Spasticity of the gastrosoleus muscle is related to the development of reduced passive dorsoflexion of the ankle in children with cerebral palsy. Acta Othopaedica 2011;82:744-8

11. Kase K, Martin P, Yasukawa A. Kinesio taping in pediatrics fundamental and whole body taping. Edisi ke-2. USA: Kinesio USA, LCC; 2006.
12. Kilbreath SL, Perkins S, Crosbie J, McConnel J. Gluteal taping improves hip ekstension during stance phase of walking following stroke. Autralian J Physiotherapist 2006;52 1:53-6.

13. Rustyanto D. Pengaruh passive streching menggunakan abduction brace terhadapt pengurangan kontraktur otot adduktor hip anak palsi serebral tipe spastik di YPAC Makassar [skripsi]. Makassar: Universitas Hasanuddin, 2010.

14. Ploughman M. A Review of brain neuroplasticity and implicatons for the physiotherapeutic management of stroke. Physiotherapy Canada;2002:164-78. 